\title{
Evaluation of Pozzolanic Activity for Effective Utilization of Dredged Sea Soil
}

\author{
Hoon Moon ${ }^{1)}$, Ji-Hyun Kim¹), Jae-Yong Lee ${ }^{1)}$, Soo-Gon Kim²), and Chul-Woo Chung ${ }^{1), *}$
}

(Received February 2, 2017, Accepted September 5, 2017, Published online December 7, 2017)

\begin{abstract}
In this work, pozzolanic activities of dredged sea soil from two different sources (South Harbor at Busan and Jangsaengpo Harbor at Ulsan) in Republic of Korea were investigated. Dredged sea soil used for this work has passed through a patented purification process, and particle size distribution, X-ray fluorescence, X-ray diffraction, and thermogravimetry/differential thermal analysis (TG/DTA) were utilized to understand its chemical and mineralogical characteristics. Temperature for heat treatment of dredged sea soil were determined using data obtained from TG/DTA, and pozzolanic activities of dredged sea soil samples were investigated by tracking the amount of calcium hydroxide spent for pozzolanic reaction as well as by monitoring the enhancement on 28 day compressive strength. According to the results, dredged sea soil samples from Jangsaengpo Harbor, which contains some amount of silt sized minerals, showed clear pozzolanic activity after heat treatment at $500{ }^{\circ} \mathrm{C}$. However, dredged sea soil samples from South Harbor did not exhibit strong pozzolanic reaction due to its larger particle size. At least, it was found that dredged sea soil samples have possibility to be used as a pozzolanic material after proper heat treatment if the size distribution of the particle contains certain amount of silt.
\end{abstract}

Keywords: dredged sea soil, pozzolanic activity, recycling, calcium hydroxide, compressive strength.

\section{Introduction}

The amount of dredged sea soil has been increasing due to the increase in maintenance and construction projects of harbors. The dredging project is a continuous work in nature due to importance of proper water depth maintenance for ships to safely move and anchor at harbors. However, the dredging project produces a large amount of dredged sea soil as a form of environmental waste. It is known that dredged sea soil includes a variety of contaminants, organic substances and heavy metals such as cadmium, arsenic, lead, etc. (Bae and Yoon 2011; Kim 2012). It was reported that only about $10 \%$ of dredged sea soil has been recycled due to the presence of organic matters and hazardous chemicals. Also, most of such wastes, approximately up to $90 \%$, had been dumped into the coastal and offshore area (Kim et al. 2014).

Recently, disposal of dredged sea soil in such a traditional manner has become impossible due to the enforced environmental regulations, also in addition to the agreement by "London Convention on the Prevention of Marine Pollution by Dumping Wastes and Other Matters (adopted in 1996)”.

\footnotetext{
${ }^{1)}$ Department of Architectural Engineering, Pukyong National University, Busan 48513, Korea.

*Corresponding Author; E-mail: cwchung@pknu.ac.kr

${ }^{2)}$ Sindaeyang Co. Ltd, Busan 49454, Korea.

Copyright @ The Author(s) 2017. This article is an open access publication
}

For this reason, currently in Republic of Korea, dredged sea soil that was produced during various dredging works was simply sent to a storage site and buried. However, it was found that dredged sea soil has caused environmental problems at disposal site during storage period, such as bad odor and contamination of surrounding environment. Mostly these are related to contamination by organics matters and hazardous chemicals in dredged sea soil. Therefore, a strong drive was placed on dredging companies to develop a purification process to remove all organic matters as well as hazardous chemicals before storing it to the disposal site.

The purification process, developed by Sindaeyang Co. Ltd., was found to remove most of the organic matters, hazardous chemicals, and chlorides (Choi et al. 2014; Sindaeyang Co. Ltd 2014). Dredged sea soil, which was processed through such purification system, has various possibilities for recycling it as a construction material. Larger size dredged sea soil (often referred to as dredged sea sand) can be recycled as fine aggregates or be used for land reclamation (Tsuchida and Kang 2003; Watabe et al. 2004). Whereas, finer size dredged sea soil (particle sizes similar to those of silt or clay) is difficult to be used for such purposes because finer dredged sea soil can cause higher water demand in case of using it as a source of aggregate, and can cause ground subsidence if used for land reclamation (Gong et al. 2009). There is one way to effectively utilize finer dredged sea soil, which is to use it as a pozzolanic material with certain amount of heat treatment.

Various studies are being conducted for the recycling of dredged soil. As representative example clay bricks were 
produced using dredged soil by high temperature heat treatment above $1100{ }^{\circ} \mathrm{C}$ (Im et al. 2013). Wang et al. (2009) studied the possibility of utilizing silt-sized dredged soil obtained from reservoirs as lightweight aggregate by making it in the form of pellets. However, these studies did not mention about purification process of the dredged sea soil, and thus might cause potential environmental issue with the leakage of hazardous chemicals from dredged sea soil. In addition, these works (Im et al. 2013; Wang 2009) uses high temperature process that is not economical and environmentally friendly. It was noted that Samara et al. (2009) have utilized purification process and their purified dredged soil obtained from the industrial complex was used for partial replacement (up to 15\%) of fine aggregate in cement brick. It is understood that most of the work related to the dredged sea soil focused on utilizing it as a source of fine aggregate. There was almost no literature that extensively studied the application of dredged sea soil as a pozzolanic material.

In this research, the pozzolanic activity of dredged sea soil was investigated in order to utilize it as a partial replacement material for cement. Utilizing dredged sea soil as a pozzolanic material is a possible approach because dredged sea soil may exhibit the structure that is similar to clay minerals, and thus proper heat treatment of dredged sea soil can develop pozzolanic activity. The properties of pretreated (purified) dredged sea soil will be first investigated, proper temperature range for heat treatment will be determined, and the pozzolanic activity of heat-treated dredged sea soil was evaluated using X-ray diffraction (XRD) and differential thermal analysis (DTA)/thermogravimetric analysis (TGA). Using dredged sea soil as a pozzolanic material can contribute to the environment issue by (1) reducing the amount of environmental waste and (2) reducing the use of cement that is responsible for the global warming.

\section{Experimental Procedures}

\subsection{Materials}

In this study, pozzolanic activities of dredged sea soil samples collected from South Harbor at Busan (SH) and Jangsaengpo Harbor at Ulsan $(\mathrm{JH})$, both in Republic of Korea, were investigated. The dredged sea soil samples used in this work have passed through purification system patented by Sindaeyang Co. Ltd. (Choi et al. 2014; Sindaeyang Co. Ltd. 2014) because dredged sea soil without purification process cannot be used because of the secondary environmental pollution caused by heavy metals and organic substances. Details of the purification process can be found in earlier literatures (Choi et al. 2014; Sindaeyang Co. Ltd. 2014).

Chemical compositions of collected dredged sea soil samples from South Harbor of Busan (SH) and Jangsaengpo Harbor of Ulsan (JH) were analyzed by XRF 1700, X-Ray Fluorescence spectroscope (Shimadzu, Japan). Particle size distribution of dredged sea soil was also measured using LS 13320 laser diffraction particle size analyzer (Beckman Coulter, USA). Type I Portland cement, manufactured by
Ssangyong Cement Industrial Co. Ltd., was used for preparation of cement paste and mortar samples. Chemical composition of type I Portland cement is shown in Table 1.

\subsection{Heat Treatment of Dredged Sea Soil}

Thermogravimetric analysis/differential thermal analysis (TG/DTA) was performed using Bruker ASX TG-DTA 2020 model (Germany) to select proper temperature for heat treatment of dredged sea soil samples. Since the inflection points at DTA curve, as well as the weight loss associated with this thermal event, can be an indicative of dehydration in clay structure that can possibly bring pozzolanic activity from dredged sea soil, those points were selected as temperatures for heat treatment of dredged sea soil. Heat treatment of dredged sea soil was performed using SH-SK-MF $\mathrm{MoSi}_{2}$ box furnace (Samheung energy, Republic of Korea). Mineralogical analysis and crystal structure changes of dredged sea soil before and after heat treatment at specific temperatures were analyzed using Ultima IV X-ray diffractometer (Rigaku, Japan).

\subsection{Pozzolanic Activity}

Pozzolanic materials do not directly react with water. With the presence of calcium hydroxide, or with other alkali hydroxides, it reacts to form silicate or aluminosilicate structure (Le et al. 2014). Pozzolanic activity can be assessed by determining the amount of calcium hydroxide consumed by the pozzolanic reaction. However, in atmospheric condition, calcium hydroxide can also be consumed by carbonation process. To eliminate such problem, degassed nano-pure deionized $(18.30 \mathrm{M} \Omega \mathrm{cm})$ water was used, and mixing and curing process were carried out in a glove box filled with $\mathrm{N}_{2}$ gas. For comparison of pozzolanic activity of heat treated dredged sea soil, metakaolin, a very well-known pozzolanic clay mineral, was used (Dinakar et al. 2013). Water to binder ratio was set at 0.5 , and replacement ratio of heat treated dredged sea soil (or metakaolin) to cement was $10 \mathrm{wt} \%$. The blended cement paste sample was poured into a 10 by $20 \mathrm{~mm}$ cylinder mold. After curing for 1 day in a glove box filled with $\mathrm{N}_{2}$, it was demolded and further cured in a lime saturated solution for 27 days, in a glove box filled with $\mathrm{N}_{2}$ gas. XRD analyses were performed to understand the mineralogical compositions of 28 day old cement paste samples with heat treated dredged sea soil.

Pozzolanic activity of dredged sea soil was evaluated using electrical conductivity method suggested by Luxán et al. (Luxán et al. 1989). This method uses $200 \mathrm{ml}$ of $40 \pm 1{ }^{\circ} \mathrm{C}$ saturated lime solution and $5 \mathrm{~g}$ of test material, and drop in electrical conductivity after $2 \mathrm{~min}$ of material addition can be used to evaluate pozzolanic activity of a material. When the pozzolanic material is exposed to an aqueous calcium hydroxide solution, a portion of silicate or aluminosilicate that dissolves from pozzolanic material and silica reacts with the calcium component in the aqueous solution to form an insoluble calcium silicate hydrate, thereby reducing electric conductivity. Therefore, it can be inferred that the pozzolanic reactivity is higher when a material shows lower electrical conductivity. The evaluation 
Table 1 Chemical composition of portland cement.

\begin{tabular}{c|c}
\hline Chemical analysis & Content (wt \%) \\
\hline $\mathrm{CaO}$ & 53.42 \\
\hline $\mathrm{SiO}_{2}$ & 19.48 \\
\hline $\mathrm{Al}_{2} \mathrm{O}_{3}$ & 4.69 \\
\hline $\mathrm{SO}_{3}$ & 4.08 \\
\hline $\mathrm{MgO}$ & 3.11 \\
\hline $\mathrm{Fe}_{2} \mathrm{O}_{3}$ & 3.04 \\
\hline $\mathrm{K}_{2} \mathrm{O}$ & 1.32 \\
\hline $\mathrm{TiO}_{2}$ & 0.38 \\
\hline $\mathrm{P}_{2} \mathrm{O}_{5}$ & 0.20 \\
\hline $\mathrm{MnO}$ & 0.13 \\
\hline $\mathrm{ZnO}$ & 0.11 \\
\hline
\end{tabular}

criteria provided by Luxán et al. (Luxán et al. 1989) is presented in Table 2, and this criteria was used for evaluation of pozzolanic activity. To obtain time dependent changes in electrical conductivity, the measurements were extended up to $240 \mathrm{~min}$ (Choi et al. 2016).

In order to verify the results obtained from electrical conductivity measurement, TG/DTA analyses of 28 day old cement paste specimens were also performed to measure the amount of calcium hydroxide present in cement paste samples. Using the amount of calcium hydroxide present in each specimen, the pozzolanic activity of heat treated dredged sea soil was quantitatively evaluated.

\subsection{Compressive Strength}

The 28 day compressive strengths of mortar specimens were measured in order to verify beneficial effect on mechanical property by the pozzolanic reaction. Fine aggregate used for this experiment is standard sand that conforms to ISO-679. Water to binder ratio $(\mathrm{w} / \mathrm{b})$ was 0.5 , and cement to fine aggregate ratio was $1: 3$, as specified in ISO-679. The amount of dredged sea soil in the mortar was $10 \%$ by weight of the cement. Metakaolin was also used as a reference pozzolanic material for dredged sea soil. The substitution rate of metakaolin was also $10 \%$ by the weight of cement.

The compressive strength was measured according to ASTM C 109 "Standard test method for compressive strength of hydraulic cement mortars (using 2-in or [50-mm] cube specimens)". As soon as mortar was mixed, it was poured into $50 \mathrm{~mm} \times 50 \mathrm{~mm}$ cube mold and stored in the $25{ }^{\circ} \mathrm{C}$ laboratory for a day. Specimens were demolded after a day, and placed in $25^{\circ} \mathrm{C}$ lime saturated solution for addition 27 days, to ensure total of 28 day curing period. The compressive strength was measured at 28 days.

\section{Results}

\subsection{Basic Properties of Dredged Sea Soil 3.1.1 Chemical Compositions}

Table 3 shows the XRF data and loss on ignition of metakaolin and the dredged sea soil from South Harbor in Busan and Jangsaengpo harbor in Ulsan. Metakaolin contains $56.96 \%$ of $\mathrm{SiO}_{2}$ and $35.54 \%$ of $\mathrm{Al}_{2} \mathrm{O}_{3}$. $\mathrm{SH}$ contains $53.5 \%$ of $\mathrm{SiO}_{2}, 12.6 \%$ of $\mathrm{Al}_{2} \mathrm{O}_{3}, 12.8 \%$ of $\mathrm{CaO}, 3.5 \%$ of $\mathrm{SO}_{3}$, and $5.2 \%$ of $\mathrm{Fe}_{2} \mathrm{O}_{3}$. Whereas $\mathrm{JH}$ contains $65 \%$ of $\mathrm{SiO}_{2}, 13.3 \%$ of $\mathrm{Al}_{2} \mathrm{O}_{3}, 2.1 \%$ of $\mathrm{CaO}, 5.5 \%$ of $\mathrm{SO}_{3}$, and $4.7 \%$ of $\mathrm{Fe}_{2} \mathrm{O}_{3}$. JH has higher $\mathrm{SiO}_{2}$ and $\mathrm{Al}_{2} \mathrm{O}_{3}$ content than $\mathrm{SH}$, and thus if those are in amorphous state, $\mathrm{JH}$ may develop higher pozzolanic activity after heat treatment (Akindahunsi and Alade 2010). SH has higher calcium content, and it is associated with the disposal of shells due to the geographical location of South Harbor that is nearby Jagalchi fish market in Busan, Republic of Korea. The loss on ignition of metakaolin and dredged sea soil was measured by burning the materials at $550{ }^{\circ} \mathrm{C}$ for $2 \mathrm{~h}$. Loss on ignition of metakaolin, $\mathrm{SH}$, and $\mathrm{JH}$ were $3.3,8$, and $6.2 \%$, respectively.

Table 2 Evaluating pozzolanic activity by electrical conductivity measurement (Luxán et al. 1989).

\begin{tabular}{c|c}
\hline Pozzolanic activity & Variation in conductivity \\
\hline \hline Non pozzolanic & Less than 0.4 \\
\hline Variable pozzolanic & Between 0.4 and 1.2 \\
\hline Good pozzolanic & Greater than 1.2 \\
\hline
\end{tabular}


Table 3 Chemical composition of dredged sea soil and metakaolin.

\begin{tabular}{|c|c|c|c|}
\hline Chemical analysis (wt\%) & Metakaolin & $\mathrm{SH}$ & $\mathrm{JH}$ \\
\hline $\mathrm{SiO}_{2}$ & 56.96 & 53.50 & 65.07 \\
\hline $\mathrm{Al}_{2} \mathrm{O}_{3}$ & 35.65 & 12.68 & 13.30 \\
\hline $\mathrm{SO}_{3}$ & 0.23 & 3.57 & 5.54 \\
\hline $\mathrm{Fe}_{2} \mathrm{O}_{3}$ & 3.21 & 5.25 & 4.76 \\
\hline $\mathrm{CaO}$ & 1.81 & 12.80 & 2.13 \\
\hline $\mathrm{Na}_{2} \mathrm{O}$ & 0.51 & 2.97 & 2.96 \\
\hline $\mathrm{MgO}$ & 0.58 & 3.08 & 2.00 \\
\hline $\mathrm{Cl}$ & - & 2.32 & 1.56 \\
\hline $\mathrm{P}_{2} \mathrm{O}_{5}$ & - & 2.08 & 0.89 \\
\hline $\mathrm{TiO}_{2}$ & 0.31 & 0.46 & 0.52 \\
\hline $\mathrm{CuO}$ & - & 0.74 & 0.99 \\
\hline $\mathrm{ZnO}$ & - & 0.18 & 0.03 \\
\hline $\mathrm{Cr}_{2} \mathrm{O}_{3}$ & - & 0.12 & 0.17 \\
\hline $\mathrm{MnO}$ & 0.05 & 0.11 & - \\
\hline $\mathrm{SrO}$ & - & 0.07 & 0.05 \\
\hline Loss on ignition (\%) & 3.3 & 8.0 & 6.2 \\
\hline
\end{tabular}

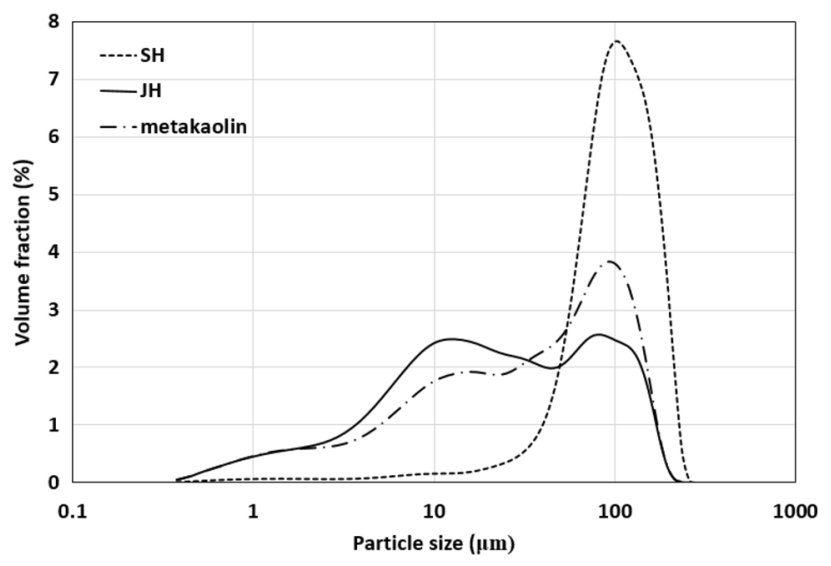

Fig. 1 Particle size distribution of dredged sea soil and metakaolin.

\subsubsection{Particle Size}

Figure 1 shows the particle size distribution of the dredged sea soil and metakaolin. The particle size of SH (dotted line) is mainly distributed in between 70 and $140 \mu \mathrm{m}$. The mean size of SH was $109.682 \mu \mathrm{m}$, and the median size was $104.911 \mu \mathrm{m}$. The particle size of SH was found to be in the range of very fine sand (Blott and Pye 2001). However, the particle size of the $\mathrm{JH}$ (solid line) had a much wider distribution that that of $\mathrm{SH}$, showing its size distribution in between 6 and $120 \mu \mathrm{m}$. The particle size of $\mathrm{JH}$ was mainly distributed in two sections, silt size (7-36 $\mu \mathrm{m}$ region) and very fine sand (57-120 $\mu \mathrm{m}$ region) (Blott and Pye 2001). The mean size of $\mathrm{JH}$ was found to be $42.479 \mu \mathrm{m}$, and its median size was $22.173 \mu \mathrm{m}$. The particle size of metakaolin (alternate long and short dash line) was mainly distributed in

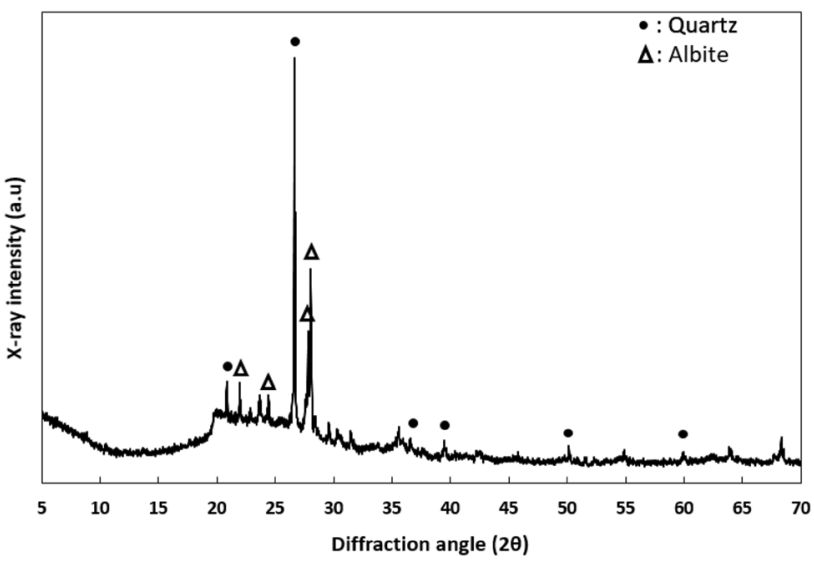

Fig. 2 XRD patterns of metakaolin.

between 20 and $130 \mu \mathrm{m}$. The mean size of metakaolin was found to be $52.495 \mu \mathrm{m}$, and its median size was $37.294 \mu \mathrm{m}$.

\subsubsection{Mineral Composition}

Figure 2 shows the XRD patterns of metakaolin. Crystalline phases found in metakaolin were quartz and albite. Figure 3 shows the XRD patterns of $\mathrm{SH}$ and $\mathrm{JH}$. Both dredged sea soil samples contained minerals such as quartz, orthoclase, and muscovite. However, these are known to be stable minerals, it is difficult to expect pozzolanic activity from them. In addition, due to the presence of highly crystalline quartz mineral, it was difficult to identify poorly crystalline clay minerals with relatively low intensity. According to Fig. 3, a weak kaolinite hump was found in $12^{\circ}-13^{\circ} 2 \theta$ area. If this hump is based on kaolin mineral, this hump will disappear after heat treatment by conversion into metakaolin, showing higher chance to 


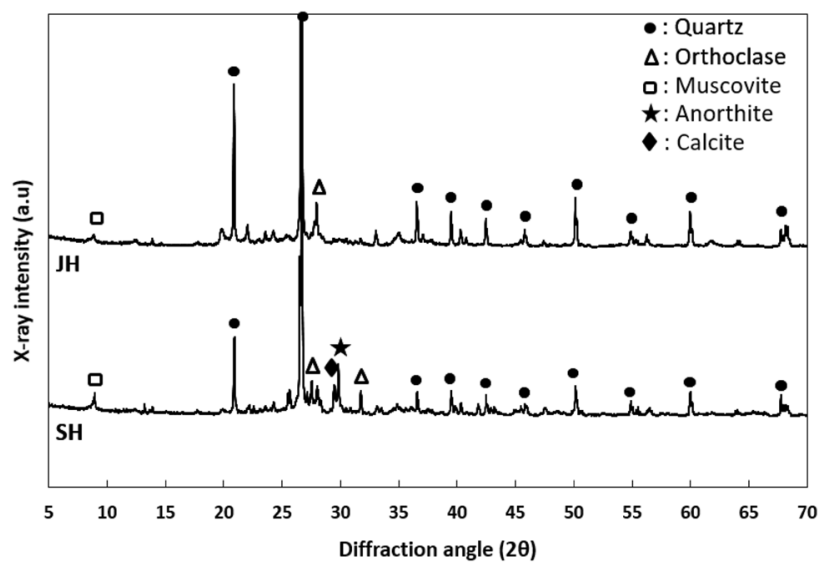

Fig. 3 XRD patterns of dredged sea soil.

present pozzolanic activity (Souri et al. 2015; Ilić et al. 2010; Vizcayno et al. 2010).

\subsubsection{Heat Treatment}

TG/DTA analysis was used to select the temperature for heat treatment of the dredged sea soil. When the inflection point occurs in the DTA graph, it means that there is a dehydration event, decomposition, or change in the crystal structure (phase conversion) of the mineral at that point. It was reported by many scientists that kaolinite has

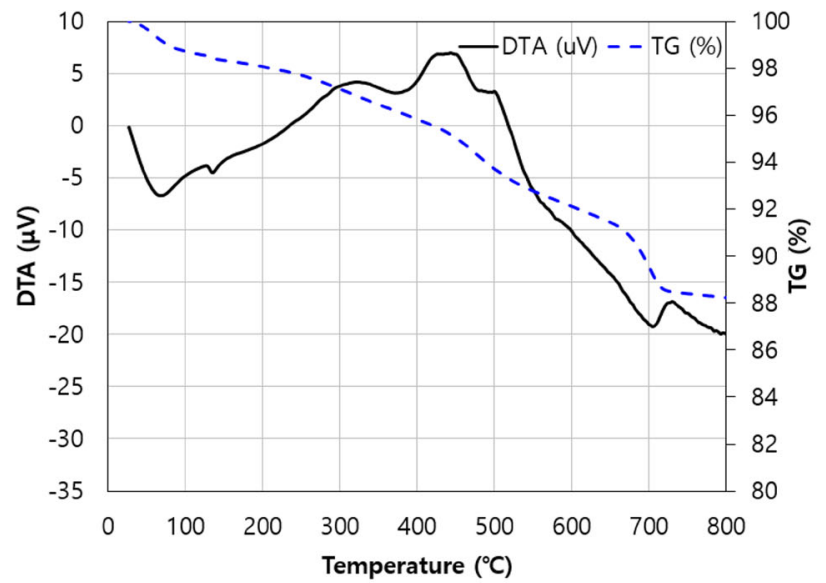

(a)

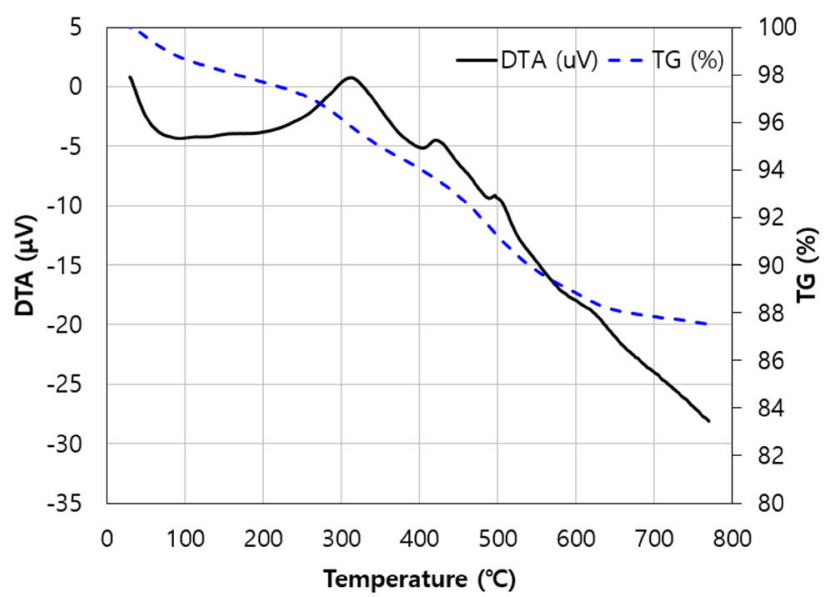

(b)

Fig. 4 TG/DTA of the dredged sea soil $(\mathbf{a} \mathrm{SH}, \mathbf{b} \mathrm{JH})$ endothermic reaction around $500{ }^{\circ} \mathrm{C}$, which is related to the conversion from kaolin to metakaolin (Ilić et al. 2010; Vizcayno et al. 2010; Kakali et al. 2001; Rabehi et al. 2014). According to Fig. 4(a), it was found that $\mathrm{SH}$ has thermal events at around 500 and $700{ }^{\circ} \mathrm{C}$. The weak thermal event at lower temperature (lower than $500{ }^{\circ} \mathrm{C}$ ) seems to be associated with the decomposition of organic matters and adhesion water. The thermal event at about $500{ }^{\circ} \mathrm{C}$ seems to be associated with conversion of metakaolin. The thermal event at $700{ }^{\circ} \mathrm{C}$ was associated with the decomposition of calcite. It was found from Fig. 4(b) that $\mathrm{JH}$ has thermal events, one at about $400{ }^{\circ} \mathrm{C}$ and the other at about $500{ }^{\circ} \mathrm{C}$. Theses temperatures were selected for heat treatment of $\mathrm{JH}$.

Figure 5 shows the XRD patterns of heat-treated $\mathrm{SH}$ and JH. After the heat treatment above $500{ }^{\circ} \mathrm{C}$, it was clearly observed that the kaolinite hump was disappeared. This indicates that dehydroxylation of kaolinite and transformation into metakaolin take place after heat treatment.

\subsection{Pozzolanic Activity \\ 3.2.1 XRD}

Figure 6 shows the XRD patterns of 28 day old cement pastes incorporating heat treated dredged sea soil. The cement paste contains portlandite, ettringite, hemi- and mono-carbonate, periclase, calcite, and unreacted $\beta-\mathrm{C}_{2} \mathrm{~S}$ (larnite). The quartz (inert mineral) peak in cement paste was originated from dredged sea soil. It was found that

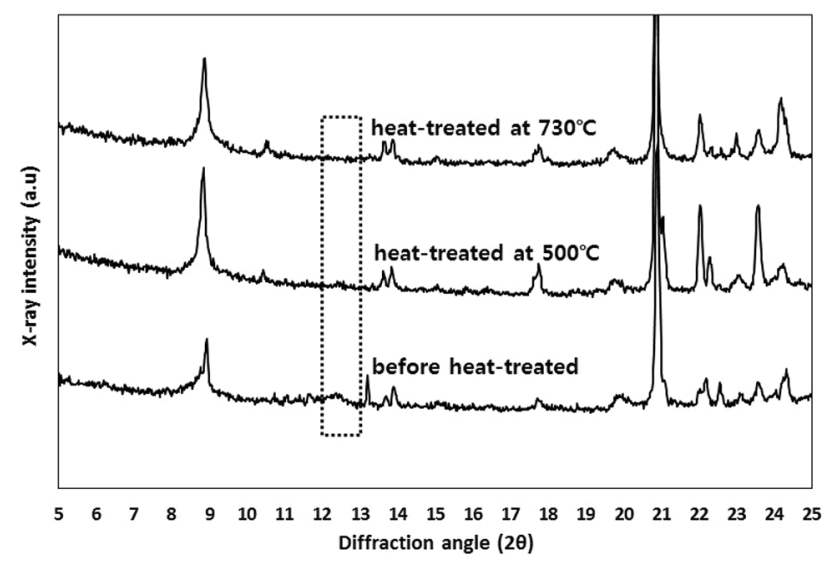

(a)

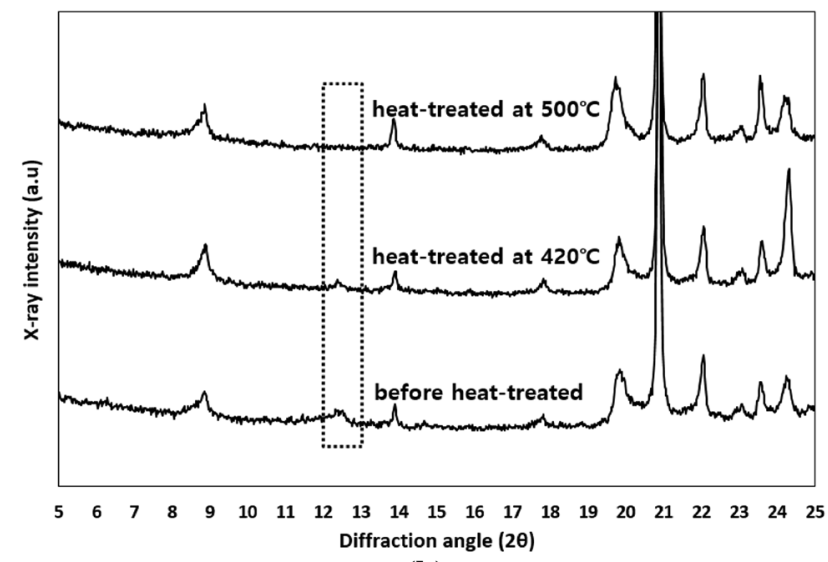

(b)

Fig. 5 Diffraction angle of $5-25^{\circ}$ of XRD patterns of heat treated dredged sea soil. (a $\mathrm{SH}, \mathbf{b} \mathrm{JH})$. 


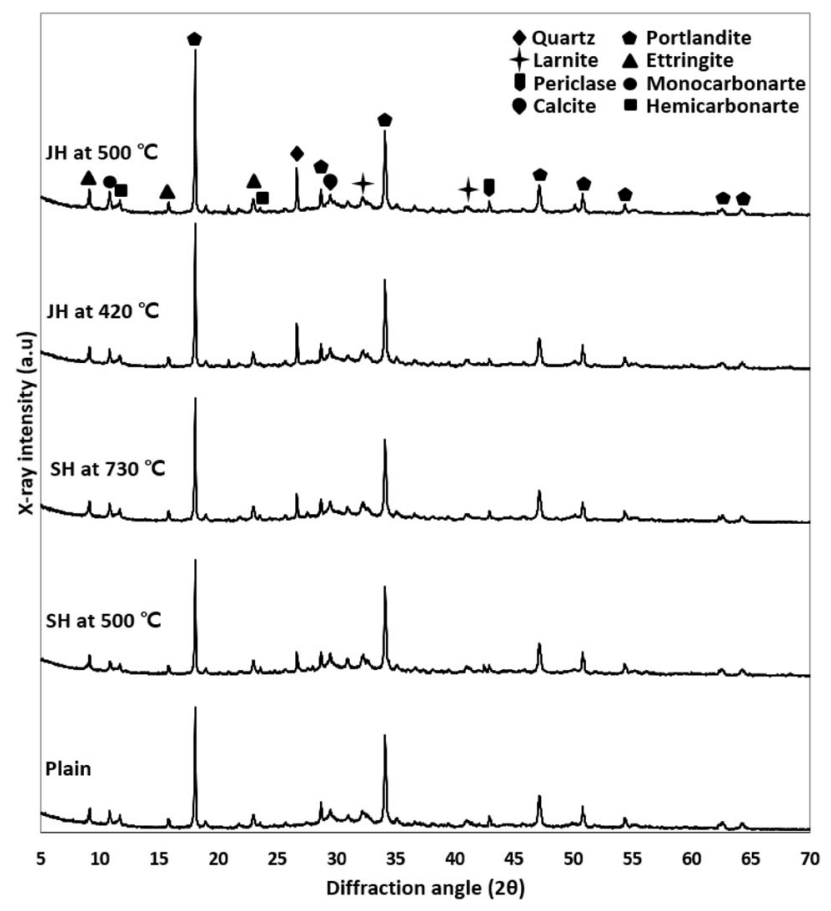

Fig. 6 XRD patterns of 28 day old cement paste (plain) and $10 \mathrm{wt} \%$ replacement of heat treated dredged sea soil $(w / b=0.5)$.

incorporation of heat treated dredged sea soil did not significantly affect phase compositions of hydrated cement paste at 28 days.

\subsubsection{Electrical Conductivity}

The pozzolanic activity was evaluated using electric conductivity method. Figure 7 shows the changes in electrical conductivity of heat treated dredged sea soil and metakaolin. Table 4 shows the difference between the initial value and the electric conductivity after $2 \mathrm{~min}$. The reduction in electrical conductivity of metakaolin at 2 min was 4.61 . At the same time, the electrical conductivity of $\mathrm{JH}$ at $500{ }^{\circ} \mathrm{C}$ sample was 1.26. Large difference was observed between metakaolin and $\mathrm{JH}$ at $500{ }^{\circ} \mathrm{C}$ sample although both materials fall in the category of good pozzolanic activity. The electrical conductivity of $\mathrm{JH}$ at $420{ }^{\circ} \mathrm{C}$ sample was 0.62 , showing variable pozzolanic activity.

According to Fig. 7, the electrical conductivities of both SH samples (at 500 and $730^{\circ} \mathrm{C}$ ) increased. This behavior seems to be associated with the presence of soluble salts that resides in the dredged sea soil. In addition, the conversion from calcite to lime (also note the thermal data in Fig. 4(a)) with $\mathrm{SH}$ at $730{ }^{\circ} \mathrm{C}$ sample has contributed to the increase in ionic concentration due to the hydration of lime $(\mathrm{CaO}+$ $\left.\mathrm{H}_{2} \mathrm{O} \rightarrow \mathrm{Ca}(\mathrm{OH})_{2}\right)$. For this reason, the pozzolanic activity of $\mathrm{SH}$ samples cannot be identified using electrical conductivity method.

\subsubsection{TG/DTA}

Figure 8 shows TG/DTA curve of 28 day old cement paste sample. For evaluation of pozzolanic activity of dredged sea soil, comparing decomposition amount of calcium hydroxide in cement paste samples that occurred at about $450{ }^{\circ} \mathrm{C}$ (Alawad et al. 2015). The weight loss before and after this thermal event was obtained using first derivative curve (maximum and minimum point) at this region. The difference of these values is the amount of water that is decomposed during this thermal event $\left(\mathrm{Ca}(\mathrm{OH})_{2} \rightarrow \mathrm{CaO}+\mathrm{H}_{2} \mathrm{O}\right)$. The weight loss of plain cement paste before calcium hydroxide decomposition was $77.425 \%$, after decomposition of calcium hydroxide, it was $74.124 \%$. The weight loss associated with the decomposition of calcium hydroxide was $3.301 \%$. Using this approach, the amounts of calcium hydroxide in cement paste samples incorporating heat treated dredged sea soil were obtained and summarized in Fig. 9 and Table 5.

According to Fig. 9 and Table 5, weight loss of cement paste incorporating $\mathrm{SH}$ at $500{ }^{\circ} \mathrm{C}, \mathrm{SH}$ at $730{ }^{\circ} \mathrm{C}$, JH at

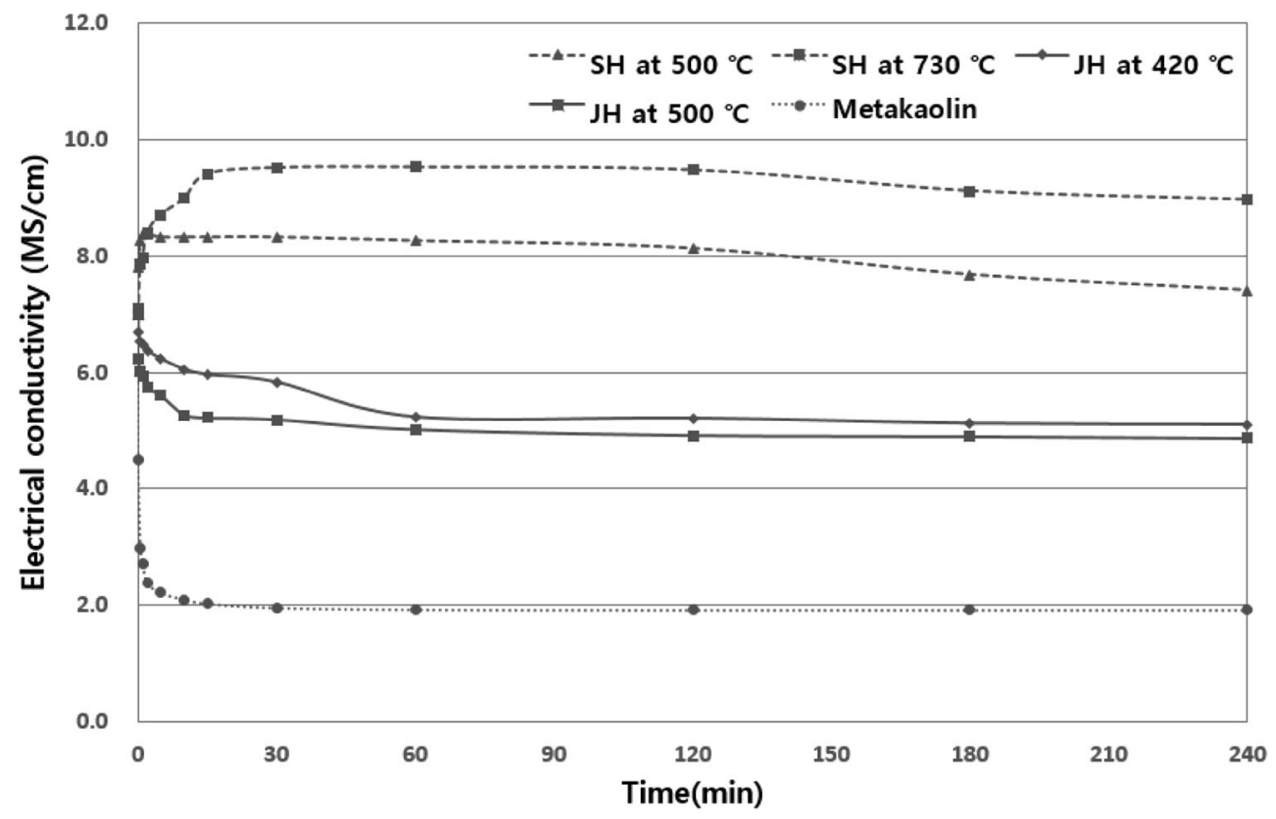

Fig. 7 Electrical conductivity of metakaolin and heat treated dredged sea soil. 
Table 4 The difference between the initial value and the electric conductivity after 2 min of metakaolin and heat treated dredged sea soil.

\begin{tabular}{c|c|c}
\hline Type & Variation in electronic conductivity & Pozzolanic activity \\
\hline \hline $\mathrm{SH}$ at $500{ }^{\circ} \mathrm{C}$ & -1.37 & - \\
\hline $\mathrm{SH}$ at $730^{\circ} \mathrm{C}$ & -1.41 & Variable pozzolanic \\
\hline $\mathrm{JH}$ at $420^{\circ} \mathrm{C}$ & 0.62 & Good pozzolanic \\
\hline $\mathrm{JH}$ at $500^{\circ} \mathrm{C}$ & 1.26 & Good pozzolanic \\
\hline Metakaolin & 4.61 & \\
\hline
\end{tabular}

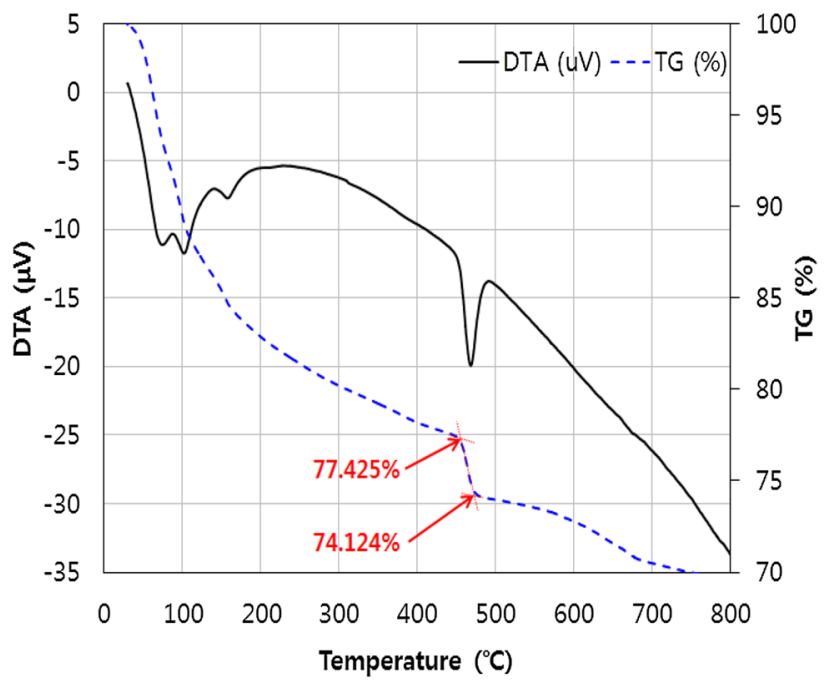

Fig. 8 TG/DTA analysis of 28 day old cement paste: plain (w/ $b=0.5)$.

$420{ }^{\circ} \mathrm{C}$, JH at $500{ }^{\circ} \mathrm{C}$, and metakaolin were $3.144,3.067$, $2.960,2.727$, and $2.605 \%$, respectively. It should be noted that the dashed line in Fig. 9 represents $90 \%$ of the amount of calcium hydroxide in the plain specimen (since dredged soil and metakaolin were replaced by $10 \mathrm{wt} \%$ of cement), and thus specimens showing lower than these value should have consumed certain amount of calcium hydroxide by pozzolanic reaction. It was found that the weight loss of cement paste incorporating $\mathrm{SH}$ at $500{ }^{\circ} \mathrm{C}$ and $\mathrm{SH}$ at $730{ }^{\circ} \mathrm{C}$ were higher than the value of dashed line (2.97\%) in Fig. 9, indicating that $\mathrm{SH}$ samples might be non pozzolanic by $\mathrm{TG} /$ DTA analyses. The weight loss of cement paste incorporating $\mathrm{JH}$ at $420{ }^{\circ} \mathrm{C}(2.96 \%)$ was similar to the value of dashed line $(2.97 \%)$. The cement paste with $\mathrm{JH}$ at $500{ }^{\circ} \mathrm{C}$ showed $2.747 \%$ of weight loss, definitely indicating that $\mathrm{JH}$ at $500{ }^{\circ} \mathrm{C}$ is a pozzolanic material although reactivity is weaker than metakaolin which showed $2.605 \%$ weight loss.

\subsection{Compressive Strength}

Figure 10 shows compressive strength data of 28 day old mortar specimens incorporating heat treated dredged soil. The compressive strength of the plain mortar was 33.84 $\mathrm{MPa}$. The compressive strength of mortar incorporating $\mathrm{SH}$ at $500{ }^{\circ} \mathrm{C}$ and $\mathrm{SH}$ at $730{ }^{\circ} \mathrm{C}$ were 33.24 and $32.61 \mathrm{MPa}$, respectively. The results were similar to that of plain mortar. The compressive strength of mortar incorporating $\mathrm{JH}$ at $420{ }^{\circ} \mathrm{C}$ was $31.62 \mathrm{MPa}$, which is lower than that of plain cement mortar. However, compressive strength of mortar incorporating $\mathrm{JH}$ at $500{ }^{\circ} \mathrm{C}$ was $37.62 \mathrm{MPa}$. Com-

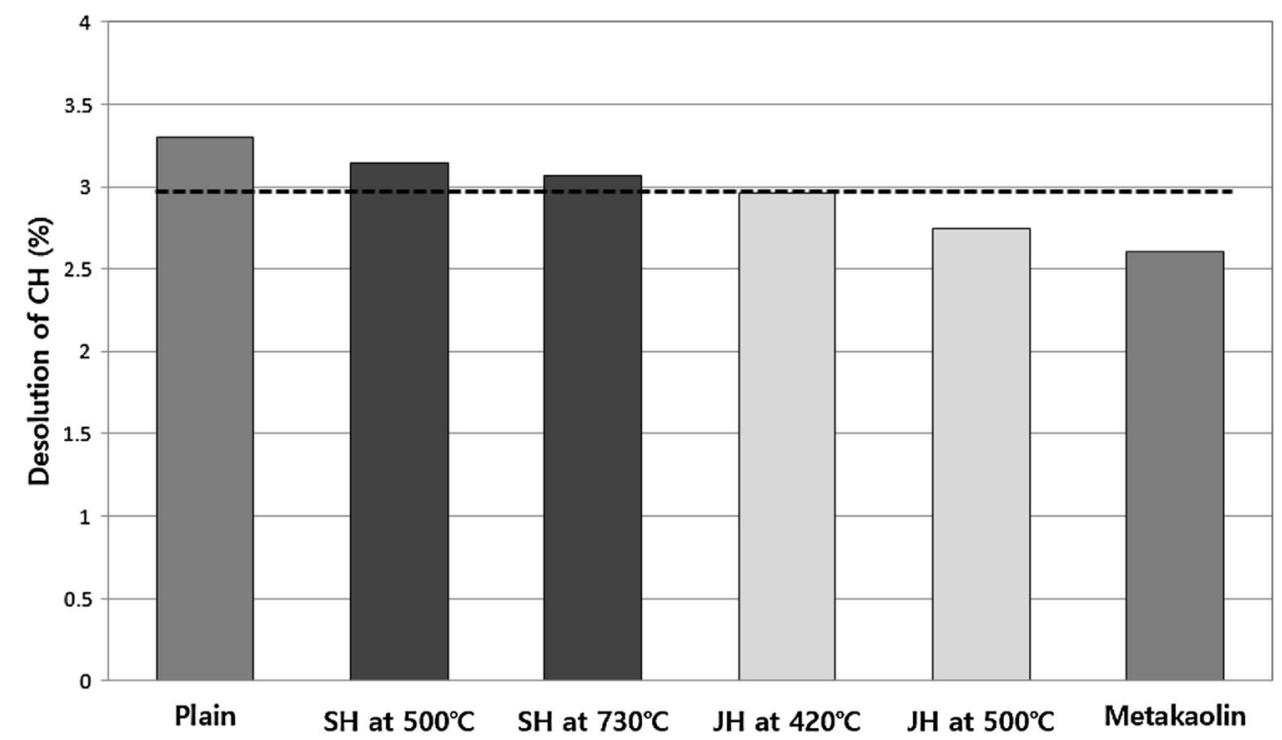

Fig. 9 The amount of weight loss in w/b 0.5 cement paste at about $450{ }^{\circ} \mathrm{C}$ (the dashed line indicates $90 \%$ of the weight loss in the plain cement paste, which considered the $10 \%$ replacement of dredged sea soil and metakaolin with the cement). 
Table 5 Decomposition amount of calcium hydroxide.

\begin{tabular}{c|c|c|c|c|c|c}
\hline & Plain cement paste & Metakaolin & \multicolumn{4}{|c}{ Heat treated temperature } \\
\cline { 4 - 6 } & & & SH at $500{ }^{\circ} \mathrm{C}$ & SH at $730{ }^{\circ} \mathrm{C}$ & $\mathrm{JH}$ at $420{ }^{\circ} \mathrm{C}$ & $\mathrm{JH}$ at $500{ }^{\circ} \mathrm{C}$ \\
\hline \hline $\begin{array}{c}\text { Weight before } \\
\text { decomposition of } \\
\text { CH (\%) }\end{array}$ & 77.425 & 76.162 & 78.534 & 76.715 & 77.444 & 76.845 \\
\hline $\begin{array}{c}\text { Weight after } \\
\text { decomposition of } \\
\text { CH (\%) }\end{array}$ & 74.124 & 73.557 & 75.390 & 73.648 & 74.484 & 74.098 \\
\hline $\begin{array}{c}\text { Amount of CH } \\
\text { decomposition } \\
(\%)\end{array}$ & 3.301 & 2.605 & 3.144 & 3.067 & 2.960 & 2.747 \\
\hline
\end{tabular}

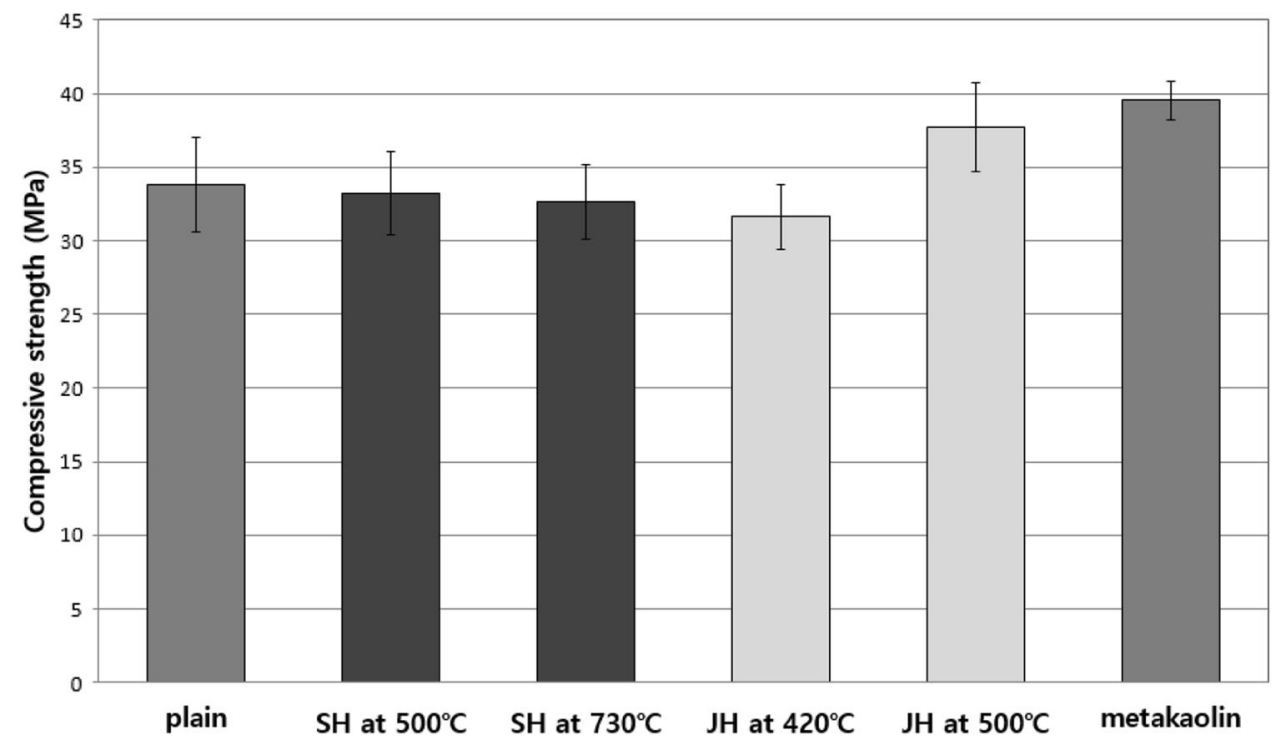

Fig. 10 Compressive strength of 28 day old cement mortar $(w / b=0.5)$ with $10 \%$ replacement of heat treated dredged sea soil.

pared to the plain cement mortar, approximately $10 \%$ increase in compressive strength was observed although it is still lower than that of metakaolin, whose compressive strength was $39.52 \mathrm{MPa}$.

\section{Discussion}

In this work, pozzolanic activities of heat treated dredged sea soils from two different sources, SH (dredged sea soil samples from South Harbor in Busan) and JH (Jangsaengpo Harbor in Ulsan), were investigated. It was found that $\mathrm{SH}$, mostly consisting of very fine sand, did not present pozzolanic activity by TG/DTA analysis. However, the 28 day compressive strength did not show significant decrease with replacement of $\mathrm{SH}$, indicating that $\mathrm{SH}$ can still meet other criteria for pozzolanic material, such as strength activity index, etc. Thus, it should be noted $\mathrm{SH}$ can be weakly pozzolanic although it was found to be non-pozzolanic by TG/DTA analysis.

$\mathrm{JH}$, which contains some amount of silt particle, was found to show pozzolanic activity by TG/DTA analysis. Analyses of pozzolanic activity using decomposition of calcium hydroxide and compressive strength showed that $\mathrm{JH}$ heat treated at $500{ }^{\circ} \mathrm{C}$ had clear pozzolanic activity. The weight loss before and after decomposition of calcium hydroxide at about $450{ }^{\circ} \mathrm{C}$ and the improvement in compressive strength by pozzolanic reaction was found to present a significant correlation. The same tendency was also observed from metakaolin, as expected and proved by other literatures (Poon et al. 2001; Sabir et al. 2001).

It was found that the pozzolanic activity of $\mathrm{JH}$ with $500{ }^{\circ} \mathrm{C}$ heat treatment was lower than that of metakaolin. It should be noted that both metakaolin and $\mathrm{JH}$ contains some amount of crystalline phases. It is known that the presence of crystalline phase in material is not beneficial in terms of pozzolanic reaction because they are more stable in highly alkaline environment than amorphous phases. The average particle size of the metakaolin was even higher than that of JH. Therefore, the lower pozzolanic activity of JH (with $500{ }^{\circ} \mathrm{C}$ heat treatment) than metakaolin can be only explained by the amount of amorphous clay mineral in the material which, in case, can be used for pozzolanic reaction. This means $\mathrm{JH}$, although heat treated, has less amount of metakaolin component than reference metakaolin material used for this work. It should be noted that the $100 \mu \mathrm{m}$ peak 
in the particle size distribution curve (Fig. 1) with JH and metakaolin might have been attributed to presence of crystalline minerals.

The incomplete pulverization of $\mathrm{JH}$ material might have also contributed to the larger particle size $(100 \mu \mathrm{m}$ peak in Fig. 1) of the JH. It was found that as received $\mathrm{JH}$, which was in a partially wet condition, behaved much like a mud, and was found to solidify when $\mathrm{JH}$ was dried. For this reason, the additional process was required in order to make uniform distribution of the particles. A separate grinding was carried out at $1,500 \mathrm{rpm}$ for $3 \mathrm{~s}$ using a Retsch RS200 (Germany) disc mill, but it is still not certain that such a short processing time is suitable to crush agglomerated clay materials.

According to the results presented in this work, the pozzolanic activity of dredged sea soil seems to be strongly related to the size of the particle, and it should have finer particle size similar to or smaller than that of silt. Heat treatment is definitely necessary for pozzolanic activity of dredged sea soil, but the amount of amorphous phases that can be a crucial part for pozzolanic reaction can vary depending on different sources of location. There should be an optimum method for dredged sea soil to be used as highly effective pozzolanic materials by controlling the particle size of the dredged sea soil and adjusting the temperature and time for heat treatment. It should be also noted that the amount of chloride must be monitored during purification process in order for heat treated dredged sea soil to be used as a pozzolanic material for reinforced concrete structure. At least, it is believed that heat treated dredged sea soil can be used as a solidifying agent in combination with lime because hydration of lime can provide necessary amount of calcium hydroxide for pozzolanic reaction of heat treated dredged sea soil.

\section{Conclusions}

This work was conducted for evaluating the pozzolanic activity of dredged sea soil with fine particle size. According to the results, following conclusions can be drawn:

(1) Heat treated dredged sea soil from South Harbor in Busan (SH) did not show pozzolanic activity by TG/ DTA analysis. Although there was no significant reduction in compressive strength with $10 \%$ replacement of $\mathrm{SH}$, it was found that $\mathrm{SH}$ cannot be used as a pozzolanic material.

(2) Heat treated dredged sea soil at $500{ }^{\circ} \mathrm{C}$ from Jangsaengpo Harbor in Ulsan (JH) did clearly present pozzolanic activity by TG/DTA analysis. The 28 day compressive strength also increased with $10 \%$ replacement of $\mathrm{JH}$.

(3) To present pozzolanic activity of dredged sea soil, smaller particle size is necessary. At least, the material should contain some portion of silt sized particles.

\section{Acknowledgements}

This research was supported by a Grant (13RDRPB066470) from Regional Development Research Program funded by Ministry of Land, Infrastructure and Transport of Korean Government.

\section{Open Access}

This article is distributed under the terms of the Creative Commons Attribution 4.0 International License (http:// creativecommons.org/licenses/by/4.0/), which permits unre stricted use, distribution, and reproduction in any medium, provided you give appropriate credit to the original author(s) and the source, provide a link to the Creative Commons license, and indicate if changes were made.

\section{References}

Akindahunsi, A. A., \& Alade, O. (2010). Exploiting the potentials of rice husk ash as supplement in cement for construction in nigeria. International Journal of Concrete Structures and Materials, 4(1), 3-8.

Alawad, O. A., Alhozaimy, A., Jaafar, M. S., Aziz, F. N. A., \& Al-Negheimish, A. (2015). Effect of autoclave curing on the microstructure of blended cement mixture incorporating ground dune sand and ground granulated blast furnace slag. International Journal of Concrete Structures and Materials, 9(3), 381-390.

Bae, Y. S., \& Yoon, G. L. (2011). The study of environmental standard and treated method for beneficial use of dredged materials. Journal of the Korean Society of Disaster Information, 7(4), 247-258.

Blott, S. J., \& Pye, K. (2001). GRADISTAT: A grain size distribution and statistics package for the analysis of unconsolidated sediments. Earth Surface Processes and Landforms, 26(11), 1237-1248.

Choi, I. J., Kim, J. H., \& Lee, S. Y. (2016). Evaluation on reactivity of by-product pozzolanic materials using electrical conductivity measurement. Journal of the Korea Institute of Building Construction, 16(5), 421-428.

Choi, J. Y., Kim, S. G., Yang, D. B., \& Kim, K. R. (2014). A novel in situ clean-up system for metal contaminated seabed sediment. Journal of Korean Environmental Dredging Society, 4(1), 49-59.

Dinakar, P., Sahoo, P. K., \& Sriram, G. (2013). Effect of metakaolin content on the properties of high strength concrete. International Journal of Concrete Structures and Materials, 7(3), 215-223.

Gong, S. L., Li, C., \& Yang, S. L. (2009). The microscopic characteristics of Shanghai soft clay and its effect on soil body deformation and land subsidence. Environmental Geology, 56(6), 1051-1056. 
Ilić, B. R., Mitrović, A. A., \& Miličić, L. R. (2010). Thermal treatment of kaolin clay to obtain metakaolin. Hemijska Industrija, 64(4), 351-356.

Im, D. S., Kim, K. N., Cho, Y. B., \& Park, J. S. (2013). Fundamental study on recycling as construction material of dredged harbor soil mixed with clay and glass frit. Korean Journal of Oil and Fat Chemistry, 30(4), 575-585.

Kakali, G., Perraki, T. H., Tsivilis, S., \& Badogiannis, E. (2001). Thermal treatment of kaolin: The effect of mineralogy on the pozzolanic activity. Applied Clay Science, 20(1), 73-80.

Kim, S. G. (2012). Remediation technologis for beneficial use of dredged materials. Journal of Korean Environmental Dredging Society, 2(1), 11-15.

Kim, J. H., Moon, H., Chung, C. W., \& Lee, J. Y. (2014). A preliminary investigation on pozzolanic activity of dredged sea soil. Journal of the Korea Institute of Building Construction, 14(6), 531-536.

Le, H. T., Nguyen, S. T., \& Ludwig, H. M. (2014). A study on high performance fine-grained concrete containing rice husk ash. International Journal of Concrete Structures and Materials (Print), 8(4), 301-307.

Luxán, M. D., Madruga, F., \& Saavedra, J. (1989). Rapid evaluation of pozzolanic activity of natural products by conductivity measurement. Cement and Concrete Research, 19(1), 63-68.

Poon, C. S., Lam, L., Kou, S. C., Wong, Y. L., \& Wong, R. (2001). Rate of pozzolanic reaction of metakaolin in highperformance cement pastes. Cement and Concrete Research, 31(9), 1301-1306.

Rabehi, B., Ghernouti, Y., \& Driss, M. (2014). Potential use of calcined silt of dam as a pozzolan in blended Portland cement. International Journal of Concrete Structures and Materials (Print), 8(3), 259-268.
Sabir, B. B., Wild, S., \& Bai, J. (2001). Metakaolin and calcined clays as pozzolans for concrete: A review. Cement \& Concrete Composites, 23(6), 441-454.

Samara, M., Lafhaj, Z., \& Chapiseau, C. (2009). Valorization of stabilized river sediments in fired clay bricks: Factory scale experiment. Journal of Hazardous Materials, 163(2), 701-710.

Sindaeyang Co. Ltd. (2014). Remediation and Solidification treatment system for stabilizing and reusing dredged soil in marine or river and Vessel equipped with the same. 1020140116687.

Souri, A., Golestani-Fard, F., Naghizadeh, R., \& Veiseh, S. (2015). An investigation on pozzolanic activity of Iranian kaolins obtained by thermal treatment. Applied Clay Science, 103, 34-39.

Tsuchida, T., \& Kang, M. S. (2003). Case studies of lightweight treated soil method in seaport and airport construction projects. In Proceedings of the 12th Asian Regional Conference on Soil Mechanics and Geotechnical Engineering, Singapore (pp. 249-252). Singapore: World Scientific Publishing.

Vizcayno, C., De Gutierrez, R. M., Castello, R., Rodriguez, E., \& Guerrero, C. E. (2010). Pozzolan obtained by mechanochemical and thermal treatments of kaolin. Applied Clay Science, 49(4), 405-413.

Wang, H. Y. (2009). Durability of self-consolidating lightweight aggregate concrete using dredged silt. Construction and Building Materials, 23(6), 2332-2337.

Watabe, Y., Itou, Y., Kang, M. S., \& Tsuchida, T. (2004). Onedimensional compression of air-foam treated lightweight geo-material in microscopic point of view. Soils and Foundations, 44(6), 53-67. 